It is proposed to extend the present Act and additional provisions until March 31, 1939, and the resolution provides for the facilitation of the establishment of industry by authorizing the Commissioners to let factories in the Special Areas. It also authorizes the Commissioners to contribute for periods not exceeding five years, not only towards income tax and rates, but also towards the rent payable in respect of new industrial undertakings. Assistance is also to be given to Site Companies established to provide factories in the Areas, and provision is made for loans not to exceed $£ 2,000,000$ in the aggregate to new undertakings for their establishment in the Areas. These proposals and the resolution led to a lively debate in which the Government accepted the Opposition suggestion of a Select Committee. Neither the Statement nor the Minister of Labour's speech indicated any rational extension of the boundaries of the Special Areas or redress of existing anomalies, and they are also silent on the questions of training labour and the improvement of communications in the Special Areas.

\section{Transmutation of the Heavy Elements}

Ar the Friday evening discourse before the Royal Institution on March 19, Lord Rutherford discussed "The Transmutation of the Heavy Elements". During the last few years, our knowledge of the transmutation of the elements by artificial methods has grown with great rapidity, and practically all the known elements have been found capable of transmutation on a small scale when bombarded by fast particles of suitable type. The bombardment of bismuth by fast deuterons is of particular interest as it leads to the production of a radioactive isotope of that element identical in radioactive and chemical properties with the natural radioactive body, radium E. This important result has been confirmed by showing that this artificially produced radium $\mathrm{E}$ gives rise to polonium-the first of the radioactive elements separated by Mme. Curie in 1897 from uranium minerals. In general, the neutron is extraordinarily effective in producing transformations in the majority of the elements. In a number of cases very slow neutrons are far more efficient in this respect than fast ones. A suitable source of neutrons for such experiments can be obtained by bombarding beryllium with $\alpha$-particles from radium. The fast neutrons can be slowed down by allowing them to pass through material containing hydrogen, for example, water or paraffin. In this way more than eighty new radioactive isotopes have been discovered, most of which break up with the emission of $\beta$-particles.

THE action of neutrons on the heaviest known element, uranium, has been the subject of close study by Hahn and Meitner during the past two years. Work with this element presents special difficulties on account of its spontaneous radioactivity. The trans-uranic elements produced by neutrons have chemical properties similar to those to be expected from eka-rhenium, eka-osmium, eka- iridium and eka-platinum, corresponding to elements of atomic numbers 93, 94, 95 and 96 respectively. Three new radioactive series are formed, two of which probably arise from the main isotope of uranium (mass 238) after the capture of a neutron, and the third may be due to a less abundant isotope of uranium (mass 235). It does not appear that the bombardment of uranium by neutrons has any effect in accelerating the natural disintegration of this element. A complex series of transformations also arises when the second heaviest element, thorium, is bombarded by neutrons.

\section{Rusting of a Meteorite}

EvER since the largest of the meteoric irons found at Cranbourne, about thirty miles south-east of Melbourne in Australia, was extracted from the sand in which it had lain buried for numberless years, it has shown a pronounced tendency to rust. This large mass, which weighed about $3 \frac{1}{2}$ tons, was presented to the Trustees of the British Museum in 1862. When first received, it was mounted on a turntable and was shown uncased. So rapid, however, was the rusting that within a short time it was decided to place it in a glazed case and keep the air within as dry as possible by means of frequently renewed supplies of lime. The effect was to slow up markedly the rate of rusting, but not to stay it altogether. It is estimated that more than 4 cwt. of rust has been removed from the meteorite since it reached the Museum. Arithmetically, therefore, it would appear as if the mass had a very long life before it, but it would have been nothing like so long because the lawrencite (ferric chloride), the cause of the mischief, is disseminated in seams and by expanding during alteration tends to split up the mass. Owing to the size and porous character of the meteorite, treatment by a surface coating which has proved so successful with other meteoric irons was out of the question.

Aвоuт a year ago, the Trustees on the advice of the Keeper of Minerals decided to substitute for the ordinary glazed case an airtight one which could be filled with dry nitrogen. At the same time the original turntable was replaced by a stronger rigid structure and the mass provided with a firmer bed. During this process forty pounds weight of rust and scale was removed. The nitrogen supply, which is concealed under the bed by the mahogany panelling, consists of the usual cylinder and oil bubblers at the entrance and egress, an extra one at a higher pressure being provided for safety at the egress side. It is necessary to pass the gas slowly through the case because of the impossibility of assuring so large a one being absolutely airtight. The glass and metal are bound together by a special hard cement. A small panel fitted with a gasket has been provided on one of the short sides to give access to the interior when necessary. The first effect of the new method has been to cover the floor of the case with an unusual amount of dust and fragments, the reason being that they had previously been maintained in the cracks or on the surface by moisture which has now gone. 